\title{
Status of formalin in commercially important fishes from the northeastern region of Bangladesh
}

\author{
TOFAEL AHMED SUMON, MD. ASHRAF HUSSAIN ${ }^{1}$, FARJANA AKHTER MITA ${ }^{2}$, \\ JOYANTA BIR $^{3}$ AND SARKER MOHAMMED IBRAHIM KHALIL ${ }^{*}$ \\ Dept. of Fish Health Management, Sylhet Agricultural University, Sylhet 3100, Bangladesh \\ ${ }^{1}$ Dept. of Fisheries Technology \& Quality Control, Sylhet Agricultural University, Sylhet \\ ${ }^{2}$ Dept. of Fisheries Management, Bangladesh Agricultural University, Mymensingh 2202, Bangladesh \\ ${ }^{3}$ Descipline of Fisheries \& Marine Resource Technology, Khulna University, Khulna 9208, Bangladesh \\ *Email: khalilsmi.fhm@sau.ac.bd
}

\begin{abstract}
The study revealed the status of formalin used in four commercially important fishes namely Rohu (Labeo rohita), Catla (Catla catla), Mrigal (Cirrhinus cirrhosus) and Hilsa (Tenualosa ilisha) from Sylhet and Moulvibazar district for a period of four months from April to July 2016. A total of 100 fish samples from different town and village markets were collected and analyzed instantly on the market to detect the presence of formalin by using a kit developed by Bangladesh Council of Scientific and Industrial Research (BCSIR). Among the analyzed fishes 46.7, 26.7, 20.0 and $13.3 \%$ of Rohu, Catla, Mrigal and Hilsa, respectively were found treated with formalin from Sylhet district. Similarly, formalin was also detected in 40, 20, 20 and $20 \%$ of investigated Rohu, Catla, Mrigal and Hilsa from Moulvibazar district, individually. There was no significant difference in formalin used between town and village market, whereas a significant difference in application of formalin in domestic and imported fishes except Catla has been identified. Two-third of imported Rohu (66.7\%) was found formalin positive followed by Hilsa (44.4\%), Mrigal (40\%) and Catla (35.7\%). Amongst the domestic fishes, presence of formalin was detected in 27.8, 18.8, 10.0 and $4.8 \%$ in Rohu, Catla, Mrigal and Hilsa, separately. This devastating use of formalin in food fishes should be banned through proper enactment of the existing laws of the country, as well as timely and appropriate implementation of government monitoring is mandatory to combat the unethical formalin use.
\end{abstract}

Keywords: Formalin, Labeo rohita, Catla catla, Cirrhinus cirrhosus, Tenualosa ilisha

\section{Introduction}

Bangladesh is ranked as fourth largest inland water fish producer and sixth largest farmed fish producer (FAO 2016). Despite the production of 3.87 million MT fish in 2015-16, still it is not enough for its huge population. That is why Bangladesh has to import a significant amount of fish from neighboring countries. In addition, the utmost challenging task for fish traders is keeping freshness of fish, as it is one of the most perishable food items (Ashie et al. 1996). Different preservation techniques are in use to preserve fish in fresh condition, among them using ice is the most common and economical. Although some fraudulent fish vendor use harmful chemical like formaldehyde that is commonly known as formalin. Besides, there have been consumer complaints and media reports that wet fish of different fish markets are contaminated with formalin; which might happen intentionally to extend the shelf life (Yeasmin et al. 2010, Ali 2013). Lack of strong regulatory controls, weak infrastructure for transport, storage and refrigeration and increasing consumer demand for fresh produce fish have also led to use fraudulent practices to increase shelf life of fish and fishery products. It is suspected that the fresh fish are sprayed with or dipped into formalin by the fish traders while transporting through domestic market chain (Yeasmin et al. 2010). 
Formaldehyde is the simplest member of aldehyde family but a very reactive chemical, where the gaseous form is known as formaldehyde and the liquid form as formalin. Its chemical formula is $\mathrm{CH}_{2} \mathrm{O}$ which is also known as methanol, commonly produced by the oxidation of methanol (Liteplo et al. 2002). Formaldehydes also widely used in textiles, plywood, papers, insulators, plastics and paint industries. Moreover, formaldehyde is one of the most effective and widely used compounds in fish culture for therapeutic and prophylactic treatment of fungal infection and external parasites of fish egg (Goon et al. 2014). However, International Agency for Research on Cancer (IARC) has classified formaldehyde as a Group-1 carcinogenic to humans and, therefore, detrimental to public health (IARC 2006). Since fish plays a major role in human nutrition and formaldehyde is carcinogenic to human, it is important to investigate the content of formaldehyde in fish, and therefore providing more information to the production of safe and hygienic food fish. Henceforth, the present study assessed the status of formalin use in four selected fish species in Sylhet and Moulvibazar region of Bangladesh.

\section{Material and Methods}

Study area: Sylhet and Moulvibazar districts were selected for the study. Samples were collected from four upazilas of these two districts such as Sylhet Sadar and Beanibazar Upazila of Sylhet district, and Moulvibazar Sadar and Barlekha Upazila of Moulvibazar district (Fig. 1). Study was conducted over a period of four months from April to July 2016.

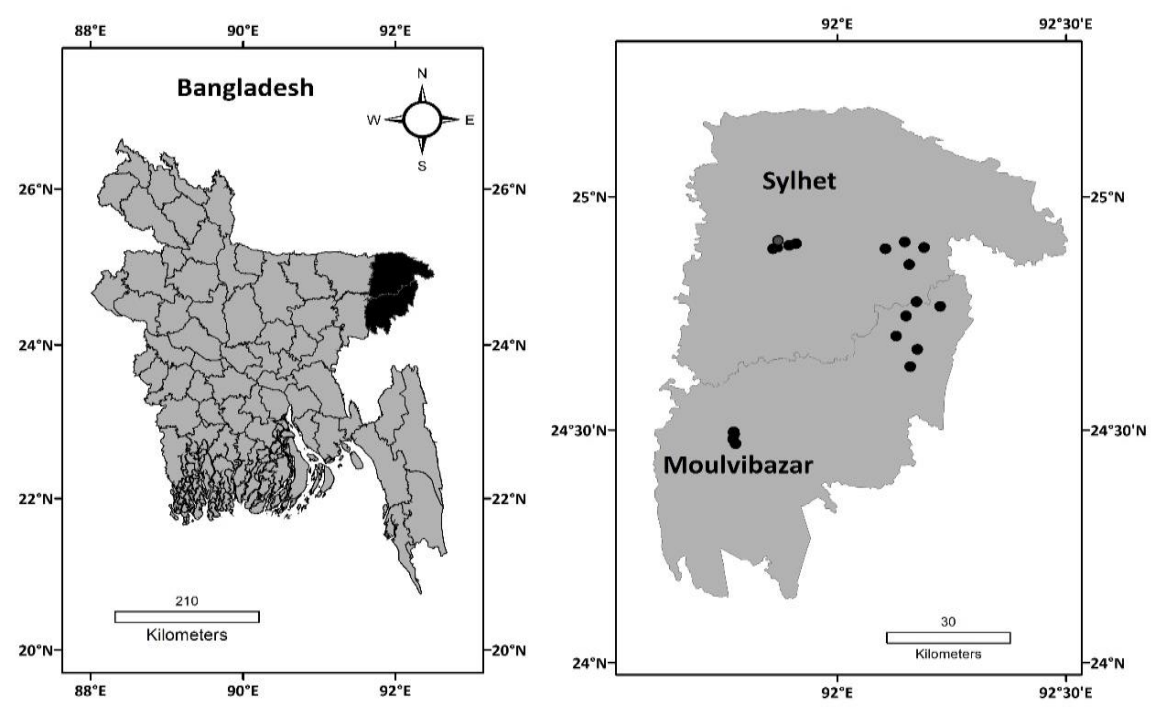

Fig. 1. Map showing the study area in Sylhet and Moulvibazar districts.

Sample collection: Four commercially important fish species, Rohu (Labeo rohita), Catla (Catla catla), Mrigal (Cirrhinus cirrhosus) and Hilsa (Tenualosa ilisha), were selected for the present study. Samples were collected from different town and village fish markets of selected four Upazilas (Table I). Both local and imported fish were tested for the detection of formalin instantly on the market. 
STATUS OF FORMALIN IN FISHES

Table I. Town and village fish markets selected for sampling

\begin{tabular}{lll}
\hline \multirow{2}{*}{ Districts } & Markets & \\
\cline { 2 - 3 } & Town & Village \\
\hline \multirow{3}{*}{ Sylhet } & Kazirbazar & Charkhai \\
\cline { 2 - 3 } & Lalbazar & Ramdhabazar \\
\cline { 2 - 3 } & Majortila & Dubag \\
\cline { 2 - 3 } & Shibganj & Boiragibazar \\
\cline { 2 - 3 } & Notunbazar & Baroigrambazar \\
\hline \multirow{3}{*}{ Moulvibazar } & Poshchimbazar & Chandgram bazar \\
\cline { 2 - 3 } & Court Road & Dasherbazar \\
\cline { 2 - 3 } & Shantibag & Hakaluki \\
\cline { 2 - 3 } & Chowmuhoni & Kathaltoli \\
\cline { 2 - 3 } & Kajirbazar & Ajimganj \\
\hline
\end{tabular}

Formalin detection: The qualitative detection of formalin was done by the detection kit developed by Bangladesh Council of Scientific and Industrial Research (BCSIR). This kit contains three different solutions labeled as Solution-1, Solution-2 and Solution-3. At first fish sample was washed with small quantity of clear water and a portion of this washed water transferred into a test tube by using a dropper. Fifteen drops of Solution-1 was added in the test tube containing washed out water. After well stirring, the solution was left for 30 seconds to react. Then 15 drops of Solution-2 were mixed with the same solution. Solution-3 was also added after 30 seconds of addition of Solution-2. The presence of formalin confirmed through change in color of solution to pink or red. Whereas no color change indicated the sample is free of formalin.

Data analysis: All the data coding and recording were done in Microsoft Excel. After that chisquare test was determined by SPSS (Version 23, IBM, USA) statistical packages.

\section{Results and Discussions}

A total of 30 samples of each fish species were analyzed for the study, among them, 15 from Sylhet and rest 15 from Moulvibazar were collected. The study found that in nearly half (46.7\%) of Rohu in Sylhet and $40 \%$ of Rohu sample in Moulvibazar were treated with formalin. Whilst, formalin was detected in $26.7 \%$ and $20 \%$ in Catla sample collected from Sylhet and Moulvibazar, respectively. Similarly, it was observed that fish vendors applied formalin in onefifth (20\%) in Mrigal of Sylhet and Moulvibazar. On the other hand, formalin presence was revealed in only 13.3\% Hilsa of Sylhet and only 2 out of 10 Hilsa of Moulvibazar. Uddin et al. (2011) observed that 70, 50, 40 and 50\% in Rohu, Catla, Mrigal and Hilsa, respectively from Dhaka city were formalin positive which is higher than the findings of the this study. Moreover, Rahman et al. (2012) reported $36.7 \%$ and $16.7 \%$ in Rohu and Catla, respectively from Sylhet city treated with formalin where there was no formalin in Mrigal and Hilsa fishes. In addition, Bhowmik et al. (2017) recorded formaldehyde content of $7.95 \pm 1.05$ to $13.48 \pm 3.07 \mathrm{mg} / \mathrm{kg}$ in Rohu and $8.46 \pm 2.14$ to $14.33 \pm 2.09 \mathrm{mg} / \mathrm{kg}$ in Catla fishes. Similarly, Hossain et al. (2008) estimated $3.95 \pm 0.2$ to $13.40 \pm 0.13 \mathrm{mg} / \mathrm{kg}$ formaldehyde content in Rohu fish. 


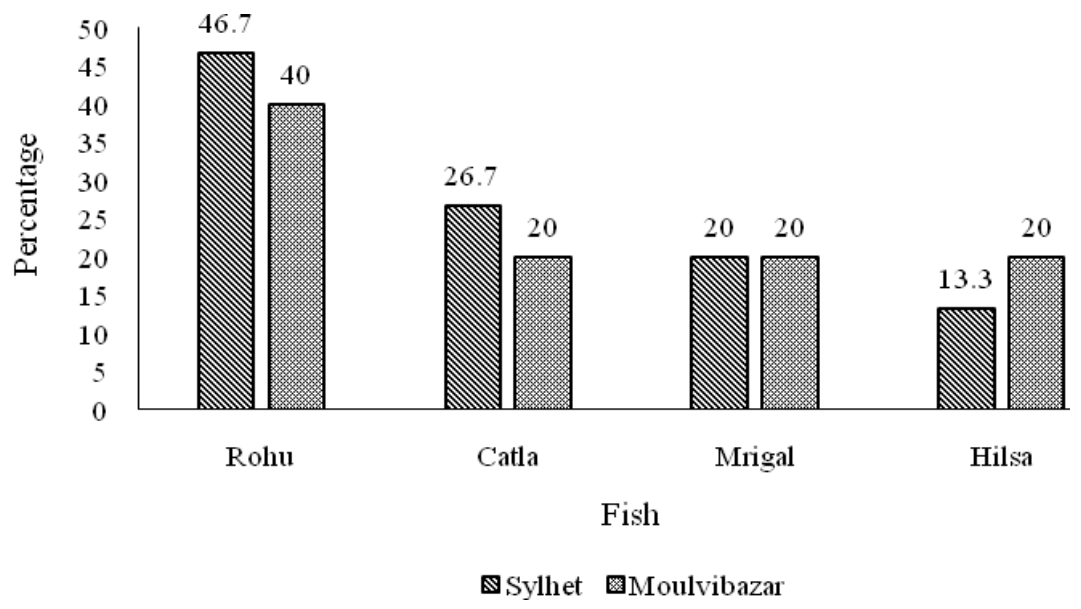

Fig. 2. Formalin treated fishes in Sylhet and Moulvibazar region

Formalin use in fishes is more frequent in town fish market when compared with village markets (Table II). It was found that fish retailers from both town and village market used formalin in more than $40 \%$ of Rohu to extent their shelf life $\left(\chi^{2}=0.068, d f=1, p=0.794\right)$. Whereas, formalin was used in over one-fourth Catla (27.8\%) of town market, but $16.7 \%$ in village markets $\left(\chi^{2}=0.497, d f=1, p=0.481\right)$. Nevertheless, $12.5 \%$ of Mrigal in village market was preserved with formalin which is almost double $(28.6 \%)$ of town markets $\left(\chi^{2}=1.205, d f=1\right.$, $p=0.272$ ). Formalin was detected in $20 \%$ of Hilsa in village market followed by $15 \%$ in town markets $\left(\chi^{2}=0.120, d f=1, p=0.729\right)$. Results of the study suggested that application of formalin in fish preservation is independent of market location, as it did not find any significant difference in using formalin between town and village markets. However, the study could not find any literature regarding differences in using formalin in fish of town and village market in Bangladesh, so this is the very first study of using formalin in village and urban markets.

Table II. Comparison of formalin use in fish of town and village market

\begin{tabular}{|c|c|c|c|c|c|c|}
\hline \multirow{2}{*}{$\begin{array}{l}\text { Fish } \\
\text { species }\end{array}$} & \multicolumn{2}{|c|}{ Town market } & \multicolumn{2}{|c|}{ Village market } & \multirow{2}{*}{$\begin{array}{l}\text { Chi- } \\
\text { square }\end{array}$} & \multirow[b]{2}{*}{$P$-value } \\
\hline & $\begin{array}{c}\text { Sample } \\
\text { size }\end{array}$ & $\%$ of formalin treated & $\begin{array}{c}\text { Sample } \\
\text { size }\end{array}$ & $\%$ of formalin treated & & \\
\hline Rohu & 20 & 45.0 & 10 & 40.0 & 0.068 & 0.794 \\
\hline Catla & 18 & 27.8 & 12 & 16.7 & 0.497 & 0.481 \\
\hline Mrigal & 14 & 28.6 & 16 & 12.5 & 1.205 & 0.272 \\
\hline Hilsa & 20 & 15.0 & 10 & 20.0 & 0.120 & 0.729 \\
\hline
\end{tabular}

Formalin use in fishes is more frequent in imported fishes rather than domestic fishes (Table III). On an average, two-third (66.7\%) of imported Rohu was found treated with formalin where only $27.8 \%$ domestic Rohu was treated with formalin $\left(\chi^{2}=4.434, d f=1, p=0.035\right)$. Fish sellers used formalin in $35.7 \%$ of imported Catla and only $18.8 \%$ of domestic Catla $\left(\chi^{2}=01.099\right.$, $d f=1, p=0.295$ ). Furthermore, four out of ten imported Mrigal was found adulterated with formalin while $10 \%$ of domestic Mrigal found formalin treated $\left(\chi^{2}=0.068, d f=1, p=0.794\right)$. 
Fish vendors preserved $44.4 \%$ imported Hilsa with formalin, however, only $4.8 \%$ domestic Hilsa was found formalin treated $\left(\chi^{2}=7.143, d f=1, p=0.008\right)$. Chi-square test indicated that formalin use in all four fishes was dependent on their origin except Catla. In our study, we found imported Rohu and Catla were contaminated much more with formalin than local which is in agreement with Hossain et al. (2008) and Yeasmin et al. (2010). In addition, fish traders have to preserve imported fish for a longer period than domestic fish which might be the possible reason for using more formalin (Hossain et al. 2008, Yeasmin et al. 2010).

Table III. Comparison of formalin use in domestic and imported fish

\begin{tabular}{lcccccc}
\hline \multirow{2}{*}{$\begin{array}{l}\text { Fish } \\
\text { species }\end{array}$} & $\begin{array}{c}\text { Sample } \\
\text { size }\end{array}$ & \% of formalin treated & $\begin{array}{c}\text { Sample } \\
\text { size }\end{array}$ & $\begin{array}{c}\text { \% of formalin } \\
\text { treated }\end{array}$ & $\begin{array}{c}\text { Chi- } \\
\text { square }\end{array}$ & $P$-value \\
\hline Rohu & 18 & 27.8 & 12 & 66.7 & 4.434 & 0.035 \\
Catla & 16 & 18.8 & 14 & 35.7 & 1.099 & 0.295 \\
Mrigal & 20 & 10.0 & 10 & 40.0 & 3.750 & 0.053 \\
Hilsa & 21 & 4.8 & 9 & 44.4 & 7.143 & 0.008 \\
\hline
\end{tabular}

\section{Conclusions}

The present study revealed some critical and important issues that needed to be solved as it is hazardous and has negative impact on human health. The study found fish wholesalers and retailers use formalin indiscriminately and unrestrainedly in fish to extend the shelf life of fish. On the other hand, our study suggests, the use of formalin is also independent of the location of market. Government should take initiatives such as monitoring throughout the supply chain, enacting the respective law, increase the awareness of public and developing infrastructure for transport and storage to prevent the misuse of formalin in fish during production, transport, storage and import. Though the findings are novel, further research is required to address formalin use in other fish species as well as the impact of using formalin on fish and human under holistic approach.

Acknowledgements: The author would like to extend his felicitation to the Department of Fish Health Management, Sylhet Agricultural University for providing him financial and laboratory support to carry out research. The authors have no conflicts of interest.

\section{Literature Cited}

Ali, A.N.M.A., 2013. Food safety and public health issues in Bangladesh: a regulatory. Eur. Food Feed Law Rev., 8(1): 31-40.

Ashie, I.N.A., J.P. Smith and B. Simpson, 1996. Spoilage and shelf-life extension of fresh fish and shellfish. Crit. Rev. Food Sci. Nutr. 36: 87-121.

Bhowmik, S., M. Begum, M.A. Hossain, M. Rahman and A.K.M.N. Alam, 2017. Determination of formaldehyde in wet marketed fish by HPLC analysis: a negligible concern for fish and food safety in Bangladesh. Egypt. J. Aquat. Res., 43(3): 245-248. DOI: https://doi.org/10.1016/j.ejar.2017.08.001.

FAO, 2016. The State of World Fisheries and Aquaculture 2016. Contributing to food security 
and nutrition for all. Rome. 200 pp.

Goon, S., M.S. Bipasha and M.S. Islam, 2014. Fish marketing status with formalin treatment in Bangladesh. Int. J. Pub. Health Sci., 3(2): 95-100.

Hossain, M.S., M.A. Rahman, T.K. Sharkar and H.M. Shahjalal, 2008. Formaldehyde content in the Rui fish (Labeo rohita) in Bangladesh and effect of formaldehyde on lipid peroxidation in Rat liver and intestinal tissues. J. Medic. Sci. 8(4): 405-409. DOI: https://doi.org/10.3923/jms.2008.405.409.

IARC (International Agency for Research on Cancer), 2006. Working group on the evaluation of carcinogenic risks to humans. World Health Organization and International Agency for Research on Cancer. Formaldehyde, 2-Butoxyethanol and 1-tert-Butoxypropan-2-ol. DOI: https://www.ncbi.nlm.nih.gov/books/NBK326468/.

Liteplo, R.G., R. Beauchamp, M.E. Meekand and R. Chénier, 2002. Concise international chemical assessment document 40: Formaldehyde. Geneva, World Health Organization 1.

Rahman, M.M., S. Ahmed, M.M. Hossen and A.K. Talukder, 2012. Detection of formalin and quality characteristics of selected fish from wet markets at Sylhet city in Bangladesh. Bangladesh Res. Public. J. 7(2): 161-169. DOI: http://www.bdresearchpublications.com/ admin/journal/upload/09326/09326.pdf.

Uddin, R., M.I. Wahid, T. Jesmeen, N.H. Huda and K.B. Sutradhar, 2011. Detection of formalin in fish samples collected from Dhaka city, Bangladesh. Stamford J. Pharmaceut. Sci., 4(1): 49-52. DOI: https://doi.org/10.3329/sjps.v4i1.8866.

Yeasmin, T., M.S. Reza, M.N.A. Khan, F.H. Shikha and M. Kamal, 2010. Present status of marketing of formalin treated fishes in domestic markets at Mymensingh district in Bangladesh. Int. J. Biologic. Res., 1(4): 21-24. 